\title{
Predicted and measured performances of near zero-energy houses: a comparison methodology
}

\author{
Thomas Recht ${ }^{*}$, Jeanne Goffart ${ }^{2}$, Laurent Mora ${ }^{1}$, Catherine Buhé ${ }^{2}$, Monika Woloszyn ${ }^{2}$ \\ ${ }^{1}$ Univ. Bordeaux, CNRS, I2M Bordeaux, 351 cours de la Libération, F-33400 Talence, France \\ ${ }^{2}$ Univ. Grenoble Alpes, Univ. Savoie Mont Blanc, CNRS, LOCIE, 73000 Chambéry, France \\ thomas.recht@u-bordeaux.fr
}

\begin{abstract}
In an energy performance verification protocol, comparing predicted and measured data is a difficult task, especially due to uncertainties surrounding the building and its environment. This work presents the development of a global approach aiming to qualify "real" performance versus expected one, by exploiting measured data (including weather and occupant's behaviour measurements). Illustrated in its first iterative phase, this approach associates joint sensitivity and uncertainty analyses with a dynamic thermal simulation model in order to gradually identify and then reduce the main sources of uncertainty on the studied performance indicator. Lastly, temporal and correlation analyses are used to identify most suitable measurement periods for the estimation of the main influential building model parameters.
\end{abstract}

\section{Introduction}

As a top-priority to tackle climate change, the building sector aims a new standard for new constructions in Europe by 2020: the near-zero energy building. If an official definition is still expected in France, experiments are in process in order to have a better grasp of performance thresholds that could be reached by those buildings. As suggested by the European Directive of 19 May 2010 (EPBD 2010) on the energy performance of buildings, these thresholds shall be a compromise between investment cost and energy savings. In this context, the COMEPOS French national project (www.comepos.fr) aims to produce a large feedback on about twenty instrumented and inhabited detached houses considered as "energy-plus" balance for all uses (Goffart et al. 2019). Their design results from a collaboration between academics, industrials and builders where optimisation studies (Recht 2016), technological innovations and know-how were associated. Measurements generated by a wide range of sensors give the opportunity to compare "real" performance with the predicted one (during the design phase), and to identify potential sources of divergence. However, several barriers must be overcome in order to rigorously compare simulated and measured data. Among these obstacles are:

- the management of the uncertainties (on predictions and on measurements),

- the coherence and the availability of measured data,
- and, finally, the capacity to calibrate the most influential parameters of the building model.

In this context, this work presents a global approach aiming to respond to that needs.

\section{Methodology}

\section{Objectives}

The pursued goal is the joint exploitation of measured data and results from a physical building model in order to produce a feedback on the design phase and information to the users. Using the measured data, the building model would be adjusted to "real" conditions, especially about weather and occupancy conditions. Assuming that the adjustment of the building model could reach a level of prediction judged "satisfactory", as well as measurements could be considered accurate, indicators intended for users could be computed. These indicators, that could evaluate a relative difference between predicted performance in adjusted conditions and "real" performance, would reflect the observed discrepancies. This would allow estimating the elementary effects between weather, occupancy, and building behaviour. The Figure 1 illustrates this type of indicators where the user can observe, on the proposed example, that "real" weather conditions explain a deterioration of about $40 \%$ on the "real" performance regarding the expected one (called "Ref."), while its quite virtuous behaviour enables an improvement by an order of $10 \%$. In the same vein, the "real" intrinsic performance of the building could be qualified regarding the simulated one in adjusted conditions (here a drop of about $20 \%$ is observed). These indicators could be computed at different time scales (e.g. daily, weekly, monthly).
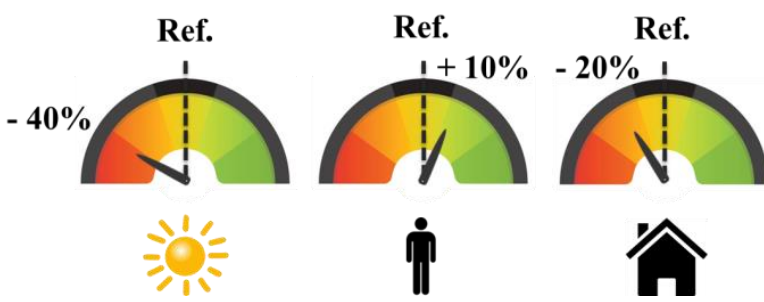

Figure 1: Illustration of the foreseen type of indicators Given the uncertainties (building characteristics, modelling hypotheses, errors from models, bias in measurements ...) the level of precision that could be obtained in the estimation process should be regarded cautiously. Thus, the goal is to extract orders of 
magnitude and tendencies. In that context, a top-down approach is foreseen for the potential identification of divergence's sources between "real" and predicted performances. Indeed, as illustrated in the Figure 2, these indicators can firstly be computed at the energy balance scale, then at the lower level (the one that distinguishes consumption and production), and, finally, at an even lower level, like the one that distinguishes envelop and equipment performances. Defaults detailed identification is therefore not the ambition of this work.

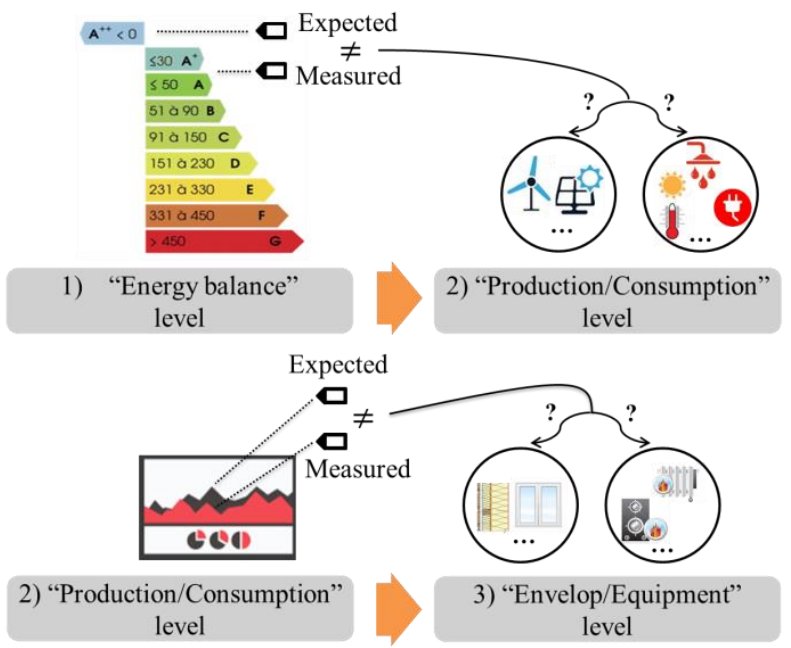

Figure 2: Illustration of the selected top-down approach with three levels of analysis

\section{Global approach}

To respond to these goals, a two-steps approach is proposed (see Figure 3). The first step is to update and then upgrade the building model used during the design phase. To update the building model, an information collection about the operating phase is proposed, making possible an initial assessment of the current knowledge level about the building. Measured data generated by sensors are, then, processed and inputted into the simulations in order to take into account "real" conditions, especially for the weather and the occupancy. After this initial update of the building model (substep 1.1), a second sub-step consists applying a joint uncertainty and sensitivity analysis in order to gradually identify and then reduce (as far as possible) the main uncertainty sources on model input parameters of the project. This sub-step (1.2) is resolutely iterative, and at each update, the uncertainty on the output decreases and the sensitivity results highlights the potential new prior sources of uncertainty (on inputs) on which the efforts can be enhanced to improve the knowledge about the project. This step is illustrated on this paper. The second step (not fully illustrated here) of the global approach is to use a model calibration method (Robillart 2015) for estimating, based on measured data, adjusted values on the main parameters of the building. This finally provides a "satisfactory" predictive model for the abovementioned goals. The key-challenge is to identify and exploit "well-chosen" measuring sequences for the estimation of studied parameters. For example, estimating a solar factor of a window on a cloudy (or without solar radiation) measurement period would undoubtedly fail. In this study, we illustrated the interest of exploiting a temporal analysis of sensitivity indices (combined with a correlation investigation) to find the better association between available measuring sequences and parameter (or group of parameters) to estimate.

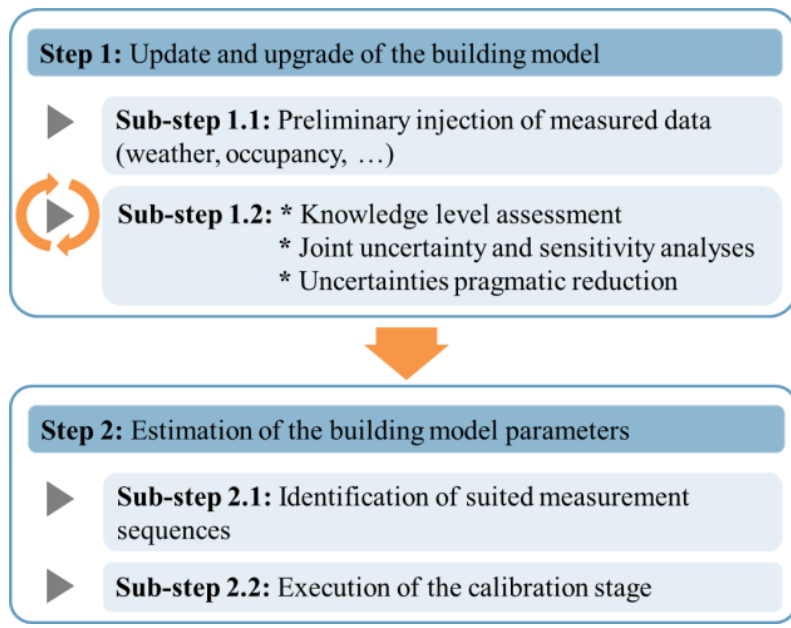

Figure 3: Illustration of the main steps of the proposed methodology

\section{Dynamic thermal simulation tool: $C O M F I E$}

Regarding other existing approaches aiming to exploit measured data by means of purely statistical models (known as "black boxes"), the chosen approach in this work is to associate measured data with a physical model, which is here a dynamic thermal simulation model called COMFIE (Peuportier and BlancSommereux 1990). Developed for a compromise between precision and calculation speed, this tool successfully passed several validation campaigns (Peuportier 2005), particularly for high energy performance buildings context (Brun et al. 2009; Recht et al. 2014; Munaretto et al. 2017). In addition, the analysis of the calibration stage results could also constitutes an interesting a posteriori verification of the model validity.

\section{Meteorological variability and inhabitant's behaviour diversity}

To compare "real" and expected performances, it is necessary to remove, in the simulation, the major uncertainty coming from weather conditions and diversity in occupant's behaviour. Otherwise the calibration of building model parameters would be impracticable. The importance of these two aspects on buildings energy performance is widely recognised, and recent models developed for considering the full extent of these variabilities through probabilistic approaches can illustrate it: Vorger et al. (2014) about occupancy, and Goffart (2013); Ligier et al. (2017) about weather. Based on the assessment, the goal is to maximise the information inputs related with measured data while looking for a compromise between instrumentation costs and level of intrusion into inhabitants' privacy. 


\section{Sensitivity and uncertainty analyses: RBD-FAST method}

An uncertainty analysis is used to evaluate the degree of variability of the simulation results caused by uncertainties on the model's inputs. In addition, the sensitivity analysis gives information about relative contributions of each uncertain input with regard to the observed global uncertainty on the output (here the heating consumption). Setting uncertainty ranges is, by definition, the critical step of this kind of methods. That is why an iterative approach is interesting to review and modify previous hypotheses based on new knowledge (coming from uncertainty and sensitivity results or new information about the project).

The RBD-FAST global sensitivity analysis (Tarantola, Gatelli, and Mara 2006) associates both analyses within a single sample of several hundreds of simulations regardless the number of studied parameters. To this end, this method exploits a decomposition of the frequency variance and a technique to reorganise outputs depending on each input using a permutation method. The estimated sensitivity indices are the Sobol's first order ones. Ranging between 0 to 1 , they represent the elementary effect of each parameter on the output uncertainty. If the sum of all indices values is significantly lower than 1 , then the interactions between parameters can be considered as high. For more information on the use of RBD-FAST in building energy simulation (BES), see Goffart et al. (2017). The method is also available in a Python code within the library SALib: https://github.com/SALib/SALib. For more information about uncertainty and sensitivity analyses, refer to Saltelli et al. (2008).

\section{Case study}

\section{General presentation}

The methodology previously described was applied, in its first phase, on one "plus-energy" house within the COMEPOS project (Figure 4). Located near Bordeaux (France), this single-storey house of about $90 \mathrm{~m}^{2}$ was delivered in September 2017, and has been inhabited by a household of three persons (one adult and two children) in the very following weeks.

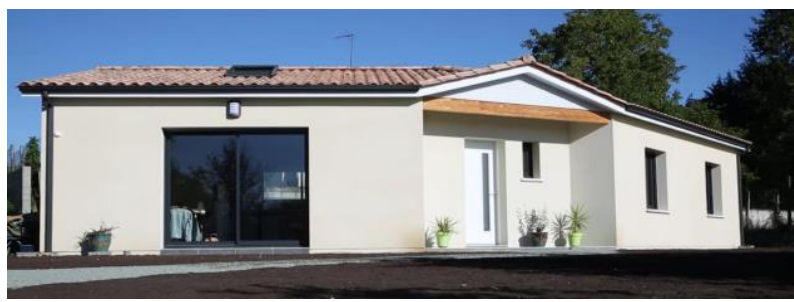

Figure 4: South view of the studied COMEPOS house

\section{Uncertain factors}

With the final aim of calibrating the building model, the mostly poorly known parameters of the project were listed in order to run joint uncertainty and sensitivity analyses. Different probability distribution functions (uniform, normal, log-normal, triangular, etc.) are used for representing the profile of uncertainty on parameters (Macdonald 2002). For a first illustration of the methodology, a uniform distribution over an interval $[a, b]$ was considered (Table 1 ). Uncertainty ranges were established according to the available level of knowledge of each input, and using expert judgment and literature (Macdonald and Strachan 2001; Spitz et al. 2012).

Table 1: Studied uncertain factors and corresponding uncertainty ranges

\begin{tabular}{|c|c|c|c|c|}
\hline Parameter & Unit & $\begin{array}{c}\text { Nominal } \\
\text { value x }\end{array}$ & $\mathrm{a}$ & $\mathrm{b}$ \\
\hline$\lambda_{P E \text { floor }}$ & $\mathrm{W} / \mathrm{m} / \mathrm{K}$ & 0,048 & $x-5 \%$ & $x+5 \%$ \\
\hline$\lambda_{G W \text { walls }}$ & $\mathrm{W} / \mathrm{m} / \mathrm{K}$ & 0,030 & $x-5 \%$ & $x+5 \%$ \\
\hline$\lambda_{G W \text { roof }}$ & $\mathrm{W} / \mathrm{m} / \mathrm{K}$ & 0,040 & $x-5 \%$ & $x+5 \%$ \\
\hline$U_{w}$ & $\mathrm{~W} / \mathrm{m}^{2} / \mathrm{K}$ & 1,85 & $x-20 \%$ & $x+20 \%$ \\
\hline$S_{w}$ & {$[-]$} & 0,50 & $x-20 \%$ & $x+20 \%$ \\
\hline$\psi_{T B \text { linear }}$ & $\mathrm{W} / \mathrm{m} / \mathrm{K}$ & $x$ & $x-50 \%$ & $x+50 \%$ \\
\hline$\psi_{T B} w$ & $\mathrm{~W} / \mathrm{m}^{2} / \mathrm{K}$ & $x$ & $x-50 \%$ & $x+50 \%$ \\
\hline$\dot{Q}_{v \text { IMV }}$ & $\mathrm{ach}$ & 0,5 & $x-50 \%$ & $x+50 \%$ \\
\hline Albedo & {$[-]$} & 0,2 & $x-20 \%$ & $x+20 \%$ \\
\hline$\dot{Q}_{v \text { inf }}$ & $\mathrm{ach}$ & 0,0 & 0,0 & 0,10 \\
\hline COP $P_{H P}$ & {$[-]$} & 2,6 & $x-40 \%$ & $x+40 \%$ \\
\hline
\end{tabular}

For example, the airflow rate for the insufflating mechanical ventilation (IMV) is not yet known, so an important uncertainty was considered around an usual value for airflow rate. The fact that the building is in high pressure via the IMV explains that infiltrations were neglected in an initial approach, even if this hypothesis is questioned by the implementation of a bound $b$ at 0.1 air changes per hour (ach). Indeed, the builder having adopted a quality process, the permeability measurement of the house is no longer mandatory by French regulations, and so the envelop airtightness is not precisely known. Concerning the air/air heat pump for heating, an annual COP in real conditions was considered, explaining the relative low value $(2,6)$ regarding the COP value in standard conditions $(3,6)$. The high uncertainty range is due to the actual lack of precision with an annual COP value modelling. Last example: standards values were considered for thermal bridges (using regulation catalogue), and thus, can be judged as inaccurate (all the more so as the construction uncertainty is added).

\section{Exploitation of Measuring Data}

According to the previous "Meteorological variability and inhabitants behaviour diversity" section, we propose here to illustrate the use of measured data linked to weather and occupancy. About exterior conditions, a temperature sensor is installed in the North façade, and the obtained data are very similar to those coming from a professional weather station located in an experimental site less than $10 \mathrm{~km}$ away. Conversely, the solar radiation sensor is inadequate because giving only a global radiation on a roof tilted surface. For that reason, weather data from the professional station (measuring the direct normal and global horizontal parts) were exploited. About interior conditions, all measured air temperatures were injected (room by room) into the simulation even if several aspects still need to be taken into account, like the heat emitted by electrical appliances (data are available) or should be integrated 
like the airflow rate of the IVM and the opening/closing of windows/shutters (date are not yet available).

\section{Results}

\section{Sensitivity and uncertainty analyses}

After the integration of measured data for a part of solicitations (weather conditions and interior temperatures), a joint uncertainty and sensitivity analysis is applied on the electrical heating consumption (because the heating system is a heat pump) with 400 simulations (corresponding to about 10 minutes of calculations). The study examines a measurement period of one month in winter (from 2017/11/20 to 2017/12/17). This sequence was chosen because the measured data were completely available (indeed, at that time, the house was recently delivered, and so, some sensors were still not working properly causing several blanks (or holes) in the data.

Figure 5 shows, with a cumulated distribution, the discrepancy of heating consumption results on the studied period after running uncertainty propagation. Several remarks can be made on the analysis of these results. First, the discrepancy is high since $95 \%$ of the results are included between 160 and $450 \mathrm{kWh}$. Secondly, the observed asymmetry on the probability law (similar to an exponential law) traduces a higher discrepancy for consumptions superior to the median than those are inferior to the median. Indeed, the first half of consumptions (in ascending order) is included between 150 and $250 \mathrm{kWh}$ while the second half is included between 250 and $500 \mathrm{kWh}$. The red line represents the measured value $(387 \mathrm{kWh})$, and can be compared to the simulated median value $(250 \mathrm{kWh})$, or to the observation that $90 \%$ of simulated consumptions are lower than the measured value. However, several aspects were not yet integrated into the updated building model, and can explain the divergences. We refer especially to the "real" heat emitted by the electrical appliances (which could currently be overestimated in the a priori schedules entered during the design phase), the schedules for the opening/closing of windows/shutters, or the metabolic heat conditioned to the "real" inhabitants' presence. Indeed, all these aspects have major influences on the heat losses and gains.

Sensitivity analysis results (Figure 6) allow to assess the own influence of each considered parameter on the heating consumption. The precision of the estimation method is $2 \%$, making several indices insignificant even negative (those on the left of the black vertical dotted line). The higher influences correspond to the coefficient of performance (COP) uncertainty $(70 \%)$ and the airflow rate related to the IMV $(20 \%)$. In addition, the indices sum being close to 1 , the interactions magnitude between the model parameter is low. Indeed, first order effects can explain nearly all the observed discrepancy. To reduce the uncertainty on the consumptions distribution, several actions could be intended. For instance, a detailed modelling of the heat pump functioning is necessary (with a variable COP value over the year). Concerning the IMV air flowrate, ongoing measurements could be soon exploited. For the airtightness of the building, a blower door test could be performed to better estimate the air leakage rate.

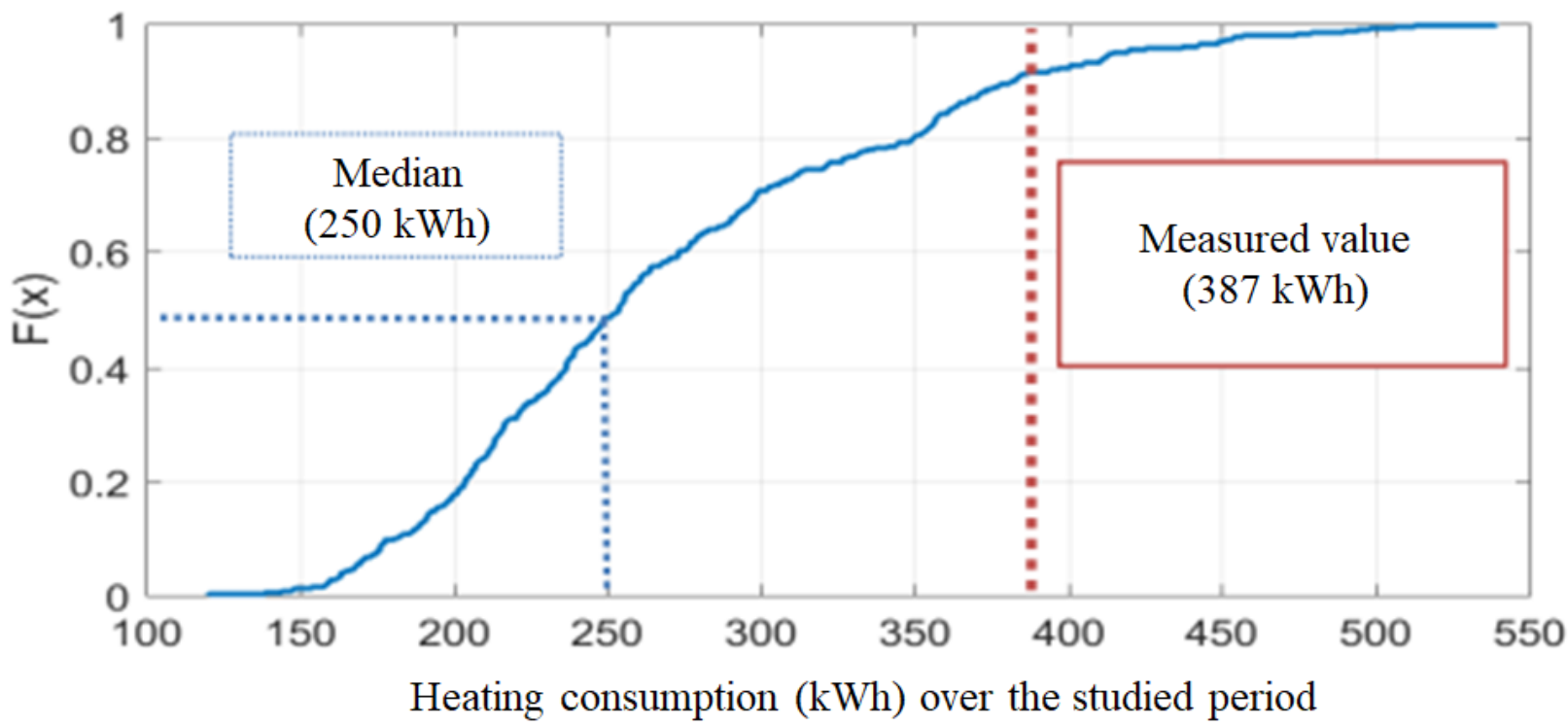

Figure 5: Representation in cumulated distribution of uncertainty on the heating consumption ( $k$ Wh) for the studied period 


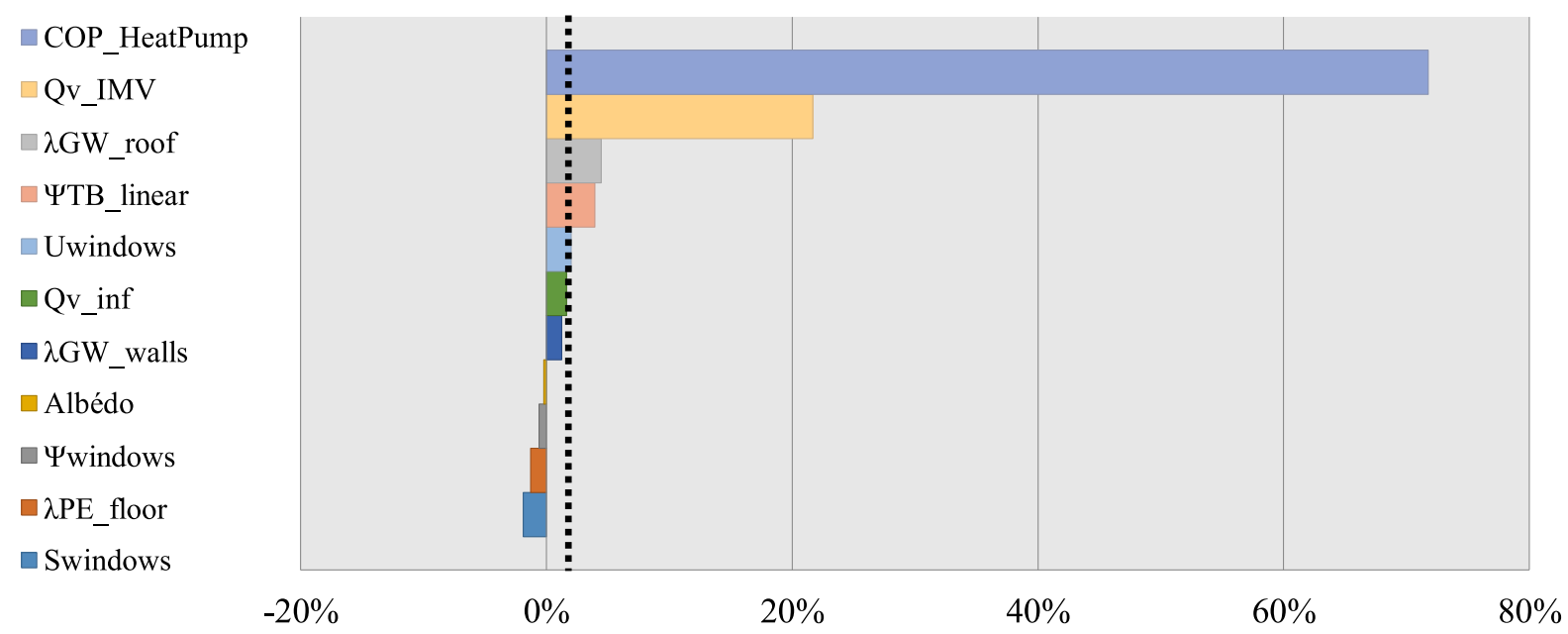

Figure 6: Sensitivity indices regarding the heating consumption for the study period

\section{Towards building model parameter estimation: interest of temporal sensitivity analysis}

Depending on intern and extern solicitations on which the building is subject to, its behaviour is changing as well as the influence of the model parameters. Figure 7 shows this temporal evaluation of sensitivity indices over the studied period. It means that a sensitivity analysis is performed at each hour of the simulation, with new sensitivity indices. Thus the sensitivity index linked to the airflow rate of the IMV can reach about $70 \%$, the COP one about $90 \%$, and, although not clearly visible, the windows solar factor one explains about $60 \%$ of the total variance at one time over the studied period. Nevertheless, these indices can be shown as "relative" in the sense that they are normalised by the total variance at each time step but the variance magnitude changes also according to the time, so the analysis must be completed by the study of the partial variances study. Partial variance corresponds to unnormalised sensitivity indices, giving information on the "absolute" influence of each parameter, and enabling to better evaluate if the measurement sequence is proper or not for parameter estimation.

For this purpose, the Figure 8 is plotted, and shows the partial variance of each parameter (the sum corresponds to the total variance of the consumption dispersion at each hourly time step). Thus, results show that the uncertainty on the COP explains most of the discrepancy, and, the relative contributions (i.e. the normalised sensitivity indices) of the airflow rate and more over of the windows solar factors are important only when the total variance is low (for example during the $23^{\text {th }}$ and $24^{\text {th }}$ November), that is less pertinent for the calibration stage. On the contrary, the COP partial variance is dominant and particularly high the first week of December. This is therefore a judicious measuring sequence for the estimation of this parameter. Beforehand, a finer modelling of the system would reduce the uncertainty on the COP value. Since the calibration of this value achieved, the update of the sensitivity analysis could enable to identify new parameters to be calibrated.

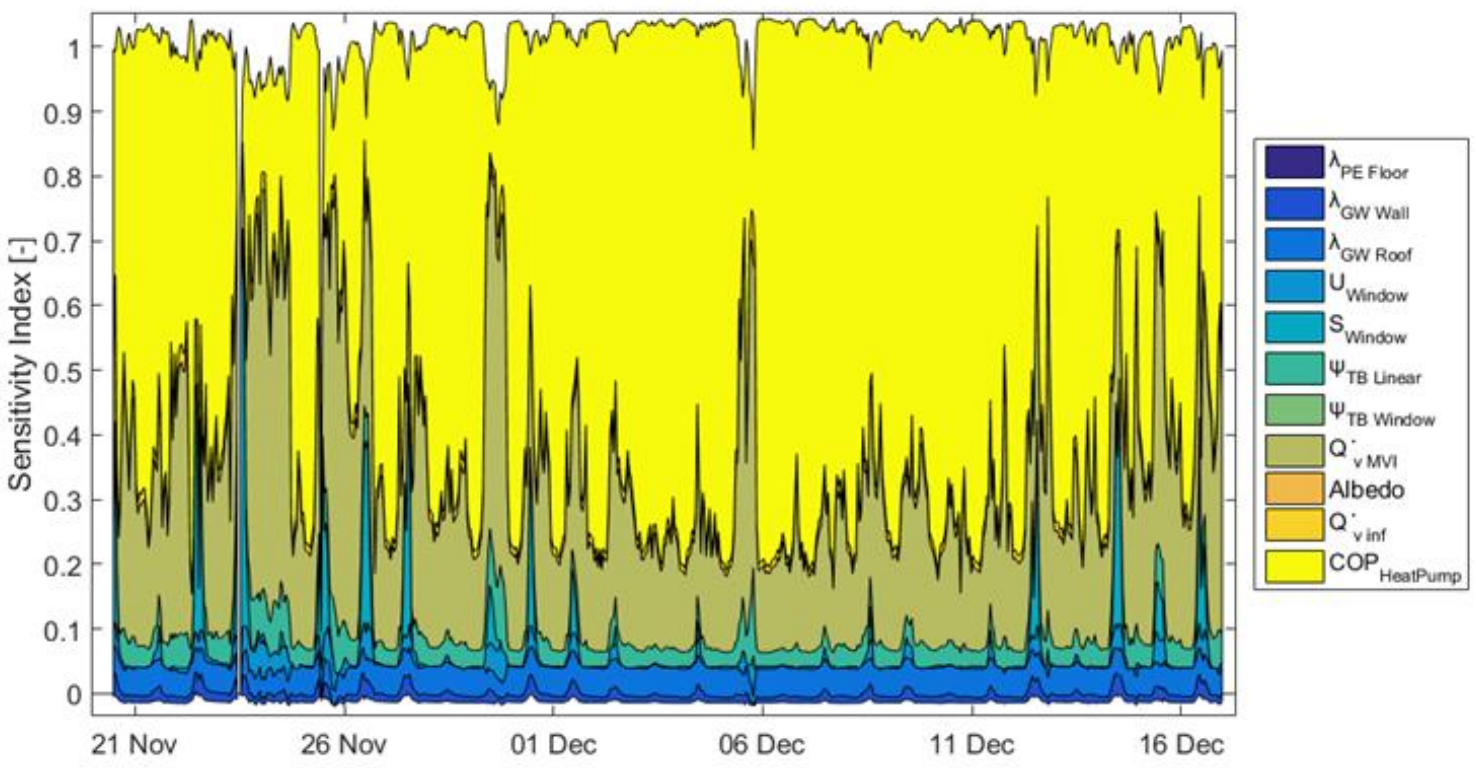

Figure 7: Temporal sensitivity indices 


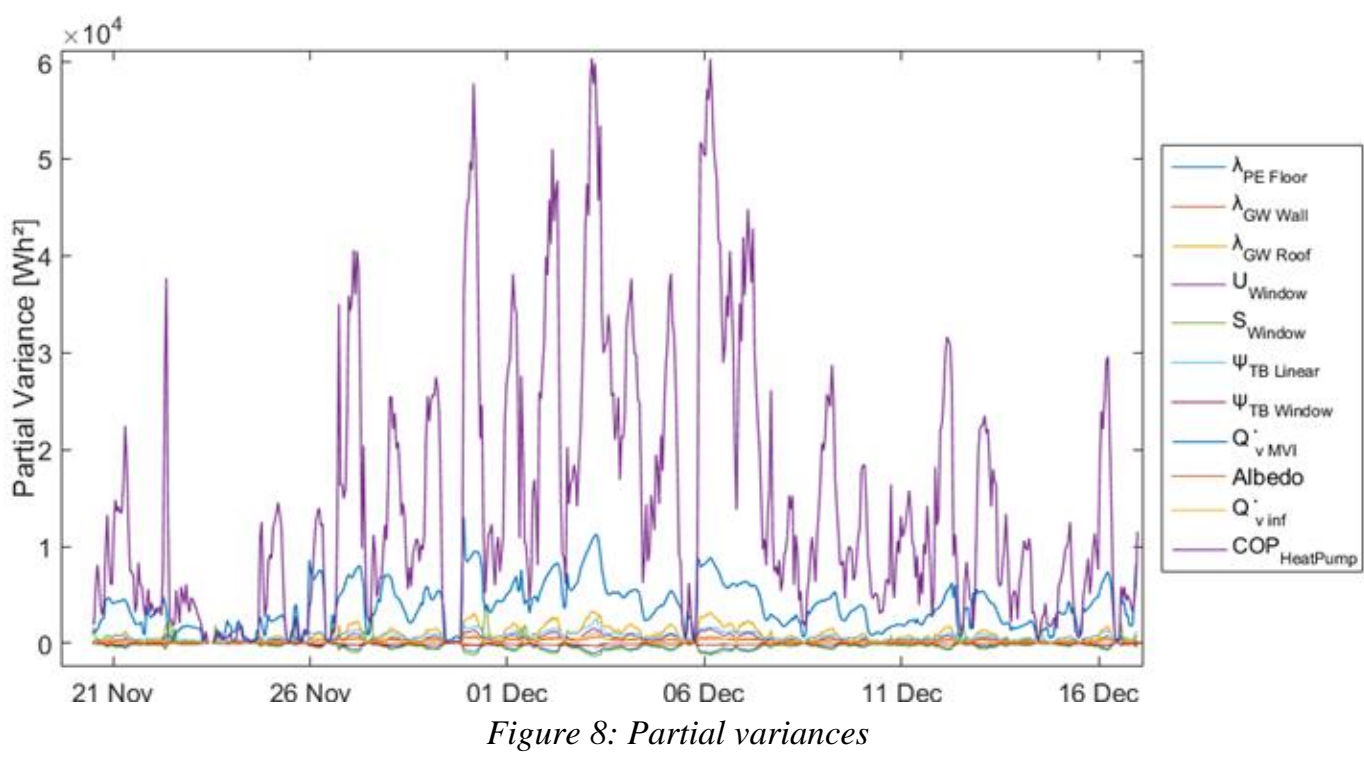

\section{Correlation investigation}

The heat electric consumption depends on the weather and especially on outdoor temperature and solar radiation. To determine the optimal sequence to identify the COP it is also interesting to quantify the relationship between daily influence of the COP on the electrical consumption and daily weather data. In the Figure 9, the daily partial variance of the most influential input, i.e. the COP during the investigation period, is plotted as a function of the average daily outdoor temperature. A third dimension is added by colour and corresponds to the daily horizontal global solar radiation.

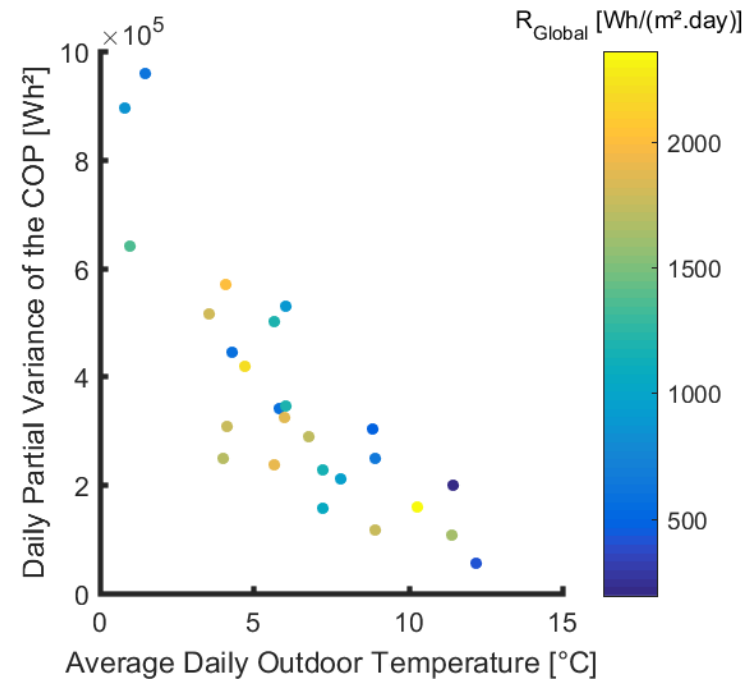

Figure 9: Daily partial variance of the COP according to the average daily outdoor temperature and the daily global radiation

We observe a strong correlation between average daily outdoor temperature and the daily partial variance of the COP. As the heat electric consumption depends on the outdoor temperature, this correlation between the most influential input on the dispersion of the heat consumption is coherent. There is no particular pattern between the daily partial variance of the $\mathrm{COP}$ and the daily solar global radiation. Nevertheless, for high value of partial variance of the $\mathrm{COP}$, i.e. high impact of the COP value on the output dispersion or variance, we observe a combination of low solar radiation and low average daily outdoor temperature.

\section{Conclusion}

This communication paper presented the development of an approach aiming to qualify, based on measured data, the "real" performance versus the predicted one. The goal is to provide a feedback on the design phase of "plus-energy" detached houses but also to give information to inhabitants, in the form of comfort and/or performance indicators. To this end, a global methodology was proposed, and divided in two main steps. It associates first a joint sensitivity and uncertainty analyses (RBD-FAST) with a dynamic energy model (COMFIE) in order to identify, and then, reduce (as far as possible) the main sources of uncertainty on the project. This step, illustrated on a real case in France, is resolutely iterative: the updated sensitivity analysis effectively enabling to highlight potential new prior uncertainty sources on which to focus the efforts. The future stake for the second step is to obtain, by Bayesian inference, an a posteriori (or calibrated) building model that would be judged "satisfactory" to address the targeted purposes. In order to succeed in this calibration stage, it is necessary to identify and exploit "well-suited" measurement sequences i.e. when the influence of the parameters to estimate is the most significant. The temporal analysis of sensitivity indices, illustrated in this paper, can favourably be used to this end, that is the next step of these works.

\section{Aknowledgements}

This work was supported by the COMEPOS project, accompanied by the French Agency for the Environment and Energy Management (ADEME), and have used the library Amapola (uncertainty and sensibility calculations tool for dynamic energy simulation), developed by (C) KOCLIKO. 


\section{References}

Brun, Adrien, Clara Spitz, Etienne Wurtz, and Laurent Mora. 2009. "Behavioural Comparison of Some Predictive Tools Used in a Low-Energy Building." In Eleventh International IBPSA Conference, 27-30. Glasgow, Scotland, 27-30 July 2009.

EPBD. 2010. "The Directive 2010/31/EU of the European Parliament and of the Council of 19 May 2010 on the Energy Performance of Buildings (Recast)." Official Journal Of the European Union, L153.

Goffart, J., Monika Woloszyn, Xavier Faure, Frédéric Wurtz, Léa Gondian, Catherine Buhé, Thomas Recht, et al. 2019. "Overview Of A Large Scale Monitoring Project Of Energy Positive Houses: Complementarity Between Simulations And Measurements.” In IBPSA World 2019. Rome (Italy).

Goffart, Jeanne. 2013. "Impact de La Variabilité Des Données Météorologiques Sur Une Maison Basse Consommation. Application Des Analyses de Sensibilité Pour Les Entrées Temporelles." Thèse de doctorat, Université de Grenoble. http://tel.archivesouvertes.fr/tel-00982150.

Goffart, Jeanne, Mickael Rabouille, and Nathan Mendes. 2017. "Uncertainty and Sensitivity Analysis Applied to Hygrothermal Simulation of a Brick Building in a Hot and Humid Climate." Journal of Building Performance Simulation 10 (1): 37-57.

Ligier, S., M. Robillart, P. Schalbart, and B. Peuportier. 2017. "Energy Performance Contracting Methodology Based upon Simulation and Measurement." In Building Simulation 2017, 10. San Francisco.

Macdonald, Iain Alexander. 2002. "Quantifying the effects of uncertainty in building simulation." Thèse de doctorat, Glasgow, Scotland: University of Strathclyde. Dept. of Mechanical Engineering. https://www.strath.ac.uk/media/departments/mechani calengineering/esru/research/phdmphilprojects/macd onald_thesis.pdf.

Macdonald, Iain, and Paul Strachan. 2001. "Practical Application of Uncertainty Analysis." Energy and Buildings $\quad 33 \quad$ (3): $\quad 219-27$. https://doi.org/10.1016/S0378-7788(00)00085-2.

Munaretto, Fabio, Thomas Recht, Patrick Schalbart, and Bruno Peuportier. 2017. "Empirical Validation of Different Internal Superficial Heat Transfer Models on a Full-Scale Passive House." Journal of Building Performance Simulation 0 (0): 1-22. https://doi.org/10.1080/19401493.2017.1331376.

Peuportier, Bruno. 2005. "Bancs d'essais de Logiciels de Simulation Thermique." In Proceedings SFT-IBPSA. La Rochelle: ENSMP.

Peuportier, Bruno, and Isabelle Blanc-Sommereux. 1990. "Simulation Tool with Its Expert Interface for the Thermal Design of Multizone Buildings." International Journal of Solar Energy 8 (2): 109-20. https://doi.org/10.1080/01425919008909714.

Recht, T. 2016. "Étude de l'écoconception de Maisons à Énergie Positive." Thèse de doctorat, Paris: École nationale supérieure des mines de Paris. https://www.theses.fr/2016PSLEM024.

Recht, T., F. Munaretto, P. Schalbart, and B. Peuportier. 2014. "Analyse de La Fiabilité de COMFIE Par Comparaison à Des Mesures. Application à Un bâTiment Passif." In Proceedings IBPSA France, 8. Arras.

Robillart, M. 2015. "Étude de Stratégies de Gestion En Temps Réel Pour Des bâTiments Énergétiquement Performants." Thèse de doctorat, École nationale supérieure des mines de Paris.

Saltelli, Andrea, Marco Ratto, Terry Andres, Francesca Campolongo, Jessica Cariboni, Debora Gatelli, Michaela Saisana, and Stefano Tarantola. 2008. Global Sensitivity Analysis: The Primer. Wiley.

Spitz, Clara, Laurent Mora, Etienne Wurtz, and Arnaud Jay. 2012. "Practical Application of Uncertainty Analysis and Sensitivity Analysis on an Experimental House." Energy and Buildings 55 (December): 459-70. https://doi.org/10.1016/j.enbuild.2012.08.013.

Tarantola, S., D. Gatelli, and T. A. Mara. 2006. "Random Balance Designs for the Estimation of First Order Global Sensitivity Indices." Reliability Engineering \& System Safety 91 (6): 717-27. https://doi.org/10.1016/j.ress.2005.06.003.

Vorger, Eric, Patrick Schalbart, and Bruno Peuportier. 2014. "Integration of a Comprehensive Stochastic Model of Occupancy in Building Simulation to Study How Inhabitants Influence Energy Performance.” In Proceedings PLEA 2014, 8. Ahmedabad (India). 